\title{
Os MAT’s - recursos de avaliação/intervenção da consciência metalinguística. Ensaios da versão portuguesa
}

\section{The MAT's - assessment/intervention metalinguistic awareness resource. Portuguese version essay}

\author{
Ana Paula Couceiro Figueira*, Antonieta Pinto** \\ *Faculdade de Psicologia e de Ciências da Educação, Universidade de Coimbra, Portugal \\ ** Universidade de Roma "La Sapienza", Roma, Itália
}

\begin{abstract}
Resumo
Apresentamos recursos para avaliação e intervenção ao nível da consciência metalinguística (Metalinguistic Awareness), previstos para três faixas etárias distintas e específicas: crianças, adolescentes e adultos. Ensaiamos a versão em língua portuguesa dos MAT’s (Testes de capacidade metalinguística - Metalinguistic Ability Tests), MAT1, MAT2 e MAT3 (O MAT-1, para crianças dos 4-6 anos, idade de transição do jardim-de-infância para a escola do $1^{0}$ ciclo do ensino básico; o MAT-2, para crianças dos 9-13 anos, idade de transição do $1^{\circ}$ para o $3^{\circ}$ ciclo; e o MAT-3, para adolescentes e adultos, na transição do secundário para o ensino superior), de Pinto (1999). Palavras-chave: consciência metalinguística; avaliação; intervenção; recursos.
\end{abstract}

\begin{abstract}
We present resources for assessment and intervention at the level of metalinguistic awareness provided for three distinct and specific age groups: children, adolescents and adults. We rehearsed the Portuguese version of the MAT's (metalinguistic ability tests - Metalinguistic Ability Test), MAT1, MAT2 and MAT3 (MAT-1, for children from 4-6 years old garden for children's transition to school the 1st cycle of basic education, the MAT-2, for children from 9-13 years of age 1 transition to the 3rd cycle, and the MAT-3, for adolescents and adults, in the transition from secondary to higher education), by Pinto (1999).

Keywords: Metalinguistic Awareness; Assessment; intervention; resources.
\end{abstract}

\section{Introdução}

Desde meados de 1970, investigadores do campo da linguística têm vindo a mostrar grande interesse no comportamento, o que revela a capacidade para refletir sobre as estruturas e funções da linguagem. Este comportamento tem sido designado de várias formas, entre outras, de capacidade (capacity), habilidade (ability), consciência (consciousness) ou conhecimento (awareness) metalinguístico. Na revisão dos contributos teóricos e empíricos relativos à consciência metalinguística, é fácil notar um considerável grau de variações terminológicas e concetuais. Esta extensa flutuação terminológica é indicadora da variedade de abordagens disciplinares que foram realizadas às dimensões metalinguísticas nos últimos vinte anos e merecem atenção diferenciada. (Pinto et al., 1999).

Na análise do tópico conhecimento metalinguístico, três abordagens são consideradas relevantes: a) a linguística, b) o desenvolvimento psicolinguístico, e c) a psicolinguística educacional (Pinto, 1999, Pinto et al., 1999).

É à linguística que devemos a criação do adjetivo "metalinguístico" e do seu substantivo correspondente, "metalinguagem", apesar de ambos os termos estarem associados ao significado que é distinto, e complementar também (Pinto et al., 1999).

Apesar das capacidades metalinguísticas surgirem em crianças de 4 ou 5 anos de idade, sendo um pré-requisito para a aquisição de competências de leitura e escrita, a subsequente aplicação das competências de escrita a atividades que inicialmente determinam processos linguístico-cognitivos básicos não é excluída.

Pinto et al. (1999) consideram que a extensão do desenvolvimento metalinguístico é muito mais amplo, progressivo e ao mesmo tempo estruturado em fases significantes do que o que foi explorado ou equacionado até ao momento. O limite inferior pode ser identificado nos primeiros comportamentos significativos que surgem entre os 5 e 6 anos de idade. O seu limite superior é constituído pelas formalizações abstratas, por vezes inúteis ou até perniciosas, que apenas uma categoria restrita de adultos (especialmente, linguistas) é capaz de construir (Pinto, 1999). Entre estes dois extremos existem formas intermédias de consciência metalinguística, estando, por exemplo, as crianças de 12 anos de idade, melhor equipadas com categorias gramaticais, que as crianças dos 6 anos, embora em desvantagem quando comparadas a alunos da escola secundária ou faculdade, se analisadas as frases que requerem uma familiaridade com certas referências culturais. O que separa os comportamentos metalinguísticos dos hipotéticos 6 anos dos do aluno hipotético do ensino secundário é equivalente à diferença entre comportamentos pré-operacionais na tarefa de 
conservação e a capacidade de resolução de problemas, que requer operações formais (Pinto et al., 1999).

\section{Os três recursos de avaliação/intervenção}

Para ultrapassar a lacuna de avaliação, surgem os três instrumentos de avaliação das capacidades metalinguísticas (MAT-1, MAT-2 e MAT-3), que permitem uma exploração das diferentes fases deste desenvolvimento (Pinto, 1999).

Mantendo, inicialmente, a estrutura do original (Pinto et al., 1999), realizando adequações linguísticas (Figueira, sd), temos:

O MAT-1 composto por 7 rubricas: Ordem das Palavras, Extensão das Palavras, Segmentação Lexical, Rimas, Substituição de Símbolos (palavras por palavras), Identificação de Palavras, Letras e Números Escritos/Impressos e Morfologia e Função de Sinais Escritos.

O Mat-2 composto por 6 secções: Compreensão, Sinonímia, Aceitabilidade, Ambiguidade, Função Gramatical e Segmentação Fonémica, num total de 96 itens.

O MAT-3 composto por duas partes, dividido em função dos tipos de significado: a primeira é direcionada para utilização denotativa e normativa da linguagem; a segunda para a utilização marcadamente conotativa: I. Compreensão e Aceitabilidade e II. Compreensão da Linguagem Figurativa.

O MAT-1. É um instrumento de avaliação das capacidades metalinguísticas, para crianças dos 4 aos 6 anos, aproximadamente. É constituído por sete testes (cf. Pinto et. al, 1999).

As sete secções foram divididas em dois grupos: um contém cinco testes de natureza geral (GML); o outro tem um caráter mais específico (SML). A distinção entre os dois grupos (GML e SML) é feita com base nos critérios seguintes: Nos testes do grupo GML, a reflexão sobre sinais é subordinada à ação recíproca das relações sintagmáticas e paradigmáticas $e$ do significado lexical e gramatical que veiculam. Por esta razão, o teste pode ser administrado através da apresentação exclusivamente oral dos itens, à exceção de alguns casos. Nos testes do grupo SML, por outro lado, a estrutura e a função dos sinais são colocados em primeiro plano, incidindo o foco nos grafemas mais enquanto objeto de conhecimento do que enquanto veículo de significado. Mais do que apenas avaliar o grau de familiaridades das crianças com diferentes tipos de convenções que regulam a escrita e a leitura, estes testes avaliam a compreensão da função de oposição que se estabelece entre cada grafema relativamente a todos os outros que revelam afinidade com ele. Por tal motivo, os testes do grupo SML apenas podem ser administrados em formato escrito (impresso) (Pinto et al., 1999).

Apesar das diferenças mencionadas anteriormente, os dois grupos estão relacionados, na medida em que ambos medem a capacidade para refletir sobre determinados tipos de significados, ainda que a níveis diferentes, em vez da mera familiaridade ou capacidade para reconhecer certos elementos. Apesar dos testes SML estarem claramente relacionados com a capacidade de leitura e escrita da criança, estes não foram selecionados como “preditores” do sucesso nesta área. O MAT-1 não tem como objetivo a predição do sucesso nas fases precoces da literacia, antes uma avaliação das capacidades cognitivo-linguísticas mais gerais (Pinto, 1999).

Assim, o grupo de testes GML é composto por cinco testes, cada um contendo um número variável de itens (entre oito e dez): 1.G) Correção da Ordem das Palavras; 2.G) Avaliação da Extensão das Palavras; 3.G) Segmentação Lexical; 4.G) Teste de Rimas; 5.G) Substituição de Símbolos. O grupo SML contempla: 1.S) Identificação de Palavras, Letras e Números Escritos/Impressos e 2.S) Morfologia e Função de Sinais Escritos. Este teste possui quatro partes: A) Legibilidade de Números, B) Legibilidade de Artigos, C) Legibilidade de Pontuação, D) Legibilidade de Textos.

Os três níveis de desempenho no MAT-1 são: O Nível 0 que corresponde às respostas que indicam que a criança ainda não entrou no sistema (definido pelas coordenadas estruturais delineadas na apresentação de cada teste), no qual deveria estar a operar naquele nível etário; o Nível 1 diz respeito a comportamentos possíveis/aceitáveis que denotam a intuição dos princípios subjacentes a cada teste (por exemplo, a dissociação de significante e significado), que não é aplicado de forma consistente, ainda a conflituar, com processos mais básicos ainda a operar; o Nível 2 indica a mestria das dinâmicas estruturais de cada item no teste.

O MAT-2. É um instrumento de avaliação das capacidades metalinguísticas, para crianças dos 9 aos 13 anos de idade (ou seja, para crianças da segunda metade da escola elementar, do $1^{\circ} 2^{\circ}$ ciclos do EB).

O Mat-2 é composto por 6 secções: Compreensão, Sinonímia, Aceitabilidade, Ambiguidade, Função Gramatical e Segmentação Fonémica, num total de 96 itens.

O teste Compreensão inclui seis pares de frases. A primeira frase de cada par (A) estabelece uma relação sintática repetida na segunda frase (B), com algumas variações.

A secção Sinonímia inclui cinco pares de frases sintaticamente diferentes, sendo quatro pares sinónimos, variando apenas na sua construção. O quinto par apresenta duas frases que aparentemente diferem apenas na sua estrutura, embora também sejam diferentes no significado ou sentido.

O teste Aceitabilidade inclui seis itens que contêm vários tipos de frases anómalas. Os cinco primeiros são caracterizados por anomalias semânticas, devido à violação de regras de compatibilidade lexical, articulada sobre as oposições humano/não humano, animado/inanimado e outros (por exemplo transitivo/intransitivo).

O teste Ambiguidade é dividido em duas partes: a primeira apresenta um conjunto de frases que contêm ambiguidades semânticas, enquanto a segunda revela ambiguidades ao nível estrutural. As ambiguidades semânticas derivam da polissemia (homónimos; homógrafas) de um termo único/simples, em que os vários significados podem modificar o sentido de toda a frase, embora as funções gramaticais de todos os outros elementos permaneçam invariáveis. Pergunta-se ao 
sujeito que (e quantos) significados tem, ou pode ter, o termo/palavra polissémico (homónimo; homógrafas) apresentado (L). Se mais do que um significado for dado, o examinador deve perguntar o sentido de toda a frase que dai resulta. Isto deve ser feito para cada um dos significados atribuídos.

O teste Função Gramatical é composto por seis itens: os três primeiros testam a compreensão das funções gramaticais do sujeito, objeto e predicado. As perguntas L (de linguagem) são voltadas para uma análise tanto da ação como dos papéis relacionados. As perguntas ML (metalinguagem) que se seguem avaliam, a um nível mais profundo, os fundamentos desta análise.

A secção Segmentação Fonémica é estruturalmente diferente da que a precede de uma forma muito distinta. A diferença básica diz respeito ao nível de análise linguística: a frase e as suas restrições às relações sintagmáticas desaparecem. O sujeito é convidado a analisar fonemas, sílabas e lexemas, de acordo com relações paradigmáticas. O significado da dimensão ML consequentemente muda relativamente à dimensão L. A distinção L-ML é relevante apenas em duas das quatro partes desta secção:

1. Semelhanças e diferenças fonético-fonológicas nos conjuntos de palavras mínimas

2. Divisão métrica silábica

3. Identificação de fonemas repetidos dentro de uma palavra

4. Formação de palavras compostas por um fonema inicial variável e uma palavra, fragmentada, fixa. Como no caso do MAT_1, o tempo não é contabilizado, embora haja limite durante a administração do teste. Num entanto, um intervalo máximo de tempo é dado para cada sessão. Mais especificamente, aos testes Compreensão, Ambiguidade, Aceitabilidade e Segmentação Fonémica é dado um máximo de 50 minutos, enquanto as secções Sinónimos e Função Gramatical são limitadas a 30 minutos. Em qualquer situação, o tempo começa a ser contabilizado após a apresentação de cada item de ensaio.

Cada secção de L e das áreas ML são codificadas de forma diferente. As respostas L são cotadas de acordo com o procedimento dicotómico certo ou errado (1 ou 0 ponto). A pontuação total de cada secção é construída pela soma das pontuações dos itens individuais. As respostas ML, por outro lado, são avaliadas item a item, de acordo com três níveis. É uma tripartição qualitativa que é quantitativamente convertida numa escala de três níveis: 0 , 1, e 2 . A pontuação total de cada secção é construída somando-se os resultados/pontuações dos itens individuais.

As características qualitativas subjacentes aos níveis ML mencionados, válidas para as cinco primeiras secções, e parcialmente para o teste Segmentação Fonémica, são os seguintes: Nível 0: Nível pré analítico: O sujeito ainda não atingiu a capacidade de analisar a soma dos índices semânticos e gramaticais nos itens apresentados; Nível 1: Análise pertinente mas insuficiente: $\mathrm{O}$ sujeito utiliza um método de análise tosco, isolando, por exemplo, pelo menos uma das pistas semântico-gramatical, ou reelaborando o conteúdo do item como uma paráfrase pertinente. A capacidade de reconstituir a arquitetura total do estímulo apresentado não está ainda desenvolvida. Os argumentos dados às respostas não são suficientes para resolver a ambiguidade que a frase contém. O Nível 2: Análise Pertinente e Exaustiva: O sujeito utiliza um método sistemático de análise, identificando todos os índices semânticos e gramaticais pertinentes no item. Deste modo, garante uma desambiguação completa do problema colocado e uma consequente independência de conteúdo linguístico que podem ser consideradas características puramente "meta".

O MAT-3. É um instrumento que visa a avaliação de capacidades metalinguísticas no adolescente e no adulto. Ao contrário do MAT-1 e MAT-2, em que foram utilizados alguns materiais já existentes na literatura anglófona sobre este tema, o MAT-3 é original, criado exclusivamente em Itália, no final de 1989, no âmbito da área disciplinar de Psicolinguística Educacional, na Universidade de Roma "La Sapienza" (Pinto et. al, 1999).

O MAT-3 é composto por duas partes, dividido em função dos tipos de significado: a primeira é direcionada para utilização denotativa e normativa da linguagem; a segunda para a utilização marcadamente conotativa:

I. Compreensão e Aceitabilidade (acceptability)

II. Compreensão da Linguagem Figurativa

O teste de Compreensão, na primeira parte, apresenta oito pares de frases, em que cada frase exemplifica diferentes aspetos semânticos de natureza léxica e gramatical. Os dois primeiros itens avaliam a compreensão das relações qualitativas, ligeiramente diferenciadas, em duas frases que são apresentadas em conjunto. As diferenças são expressas por determinadas escolhas lexicais que o sujeito tem de tomar em consideração, no sentido de avaliar se a relação qualitativa de identidade entre as duas frases é do mesmo tipo. Os terceiro e quarto itens avaliam a compreensão das relações temporais entre dois acontecimentos que são propositadamente diferenciados de forma variável para cada par de frases. No primeiro par, há uma diferença clara no significado temporal, marcado por elementos morfosintáticos salientes. No segundo par, a diferença é menos acentuada, e é predominantemente atribuída a elementos lexicais, e a variações na ordem das palavras utilizadas para cada frase. O quinto e sexto itens são pensados como um pequeno teste de compreensão morfológica, concebido de forma a repetir o mesmo elemento em frases com diferentes significados e funções. A dimensão semântica é aqui tão importante quanto a dimensão gramatical do morfema, em termos de compreensão global da frase. Finalmente, o sétimo e oitavo itens avaliam a compreensão das relações espácio-temporais, nomeadamente, as que são inclusivas/abrangentes. As diferenças de significado em cada par/conjunto de frases são, neste caso, relativamente frágeis, uma vez mais expressas por elementos lexicais que devem ser analisadas para determinar a identidade ou a diferença entre as relações apresentadas.

Estes primeiros oito itens (que somam um total de dezasseis frases) compõem um teste de compreensão que é totalmente focalizado sobre o problema da sinonímia. 
A secção Aceitabilidade é baseada nas utilizações normativas da linguagem, baseando-se no conhecimento do sujeito de regras gramaticais que são violadas num breve texto. O sujeito deverá ser capaz de reconhecer os erros, principalmente de natureza morfossintática, presentes no texto, corrigir os mesmos e, posteriormente, justificar as correções. Aqui, a dimensão L consiste na capacidade de identificar e corrigir esses erros, de modo a obter a solução completa e correta para o problema. A dimensão ML, por outro lado, consiste na capacidade em justificar cada correção, através de um duplo reconhecimento: o tipo de regra violada e as formas em que a correção se encaixa de forma adequada para o contexto da frase.

A segunda parte remete para a compreensão dos vários exemplos de linguagem figurativa: metáforas, num sentido estrito, apresentadas como frases individuais, slogans publicitários e textos poéticos breves, para um total de seis itens (dois por cada tipologia). A dimensão L nesta parte apenas é relevante no caso dos slogans publicitários, uma vez que uma parte essencial da compreensão requer a capacidade de relacionar, adequadamente, a fórmula linguística do slogan com o 'significado' social do objeto anunciado. Uma vez que este objeto é uma referência exata, especificada no item, o ‘valor verdadeiro' corresponde à pertinência com que o sujeito relaciona o slogan e o objeto. A dimensão ML, por outro lado, consiste na capacidade em analisar a técnica específica linguística que determina o humor do slogan e, portanto, os seus aspetos figurativos. Tendo em conta que a compreensão das frases metafóricas e os textos poéticos não pode ser relacionada com um valor verdadeiro específico, são criadas interpretações puramente ML com base numa análise mais ou menos profunda e plausível das relações semânticas que ligam os significados metafóricos desses itens.

Ou seja, a $1^{\text {a }}$ Parte, compreensão e aceitabilidade, compreende, na Compreensão: A. Relações qualitativas, B. Relações temporais, C. Teste morfológico, D. Relações espácio-temporais, e Aceitabilidade. A $2^{\mathrm{a}}$ Parte, Compreensão da linguagem figurativa, compreende Frases metafóricas, Slogans publicitários e Textos poéticos (cf. Figueira, sd; Pinto et al., 1999; Pinto, 1999).

\section{Referências}

Codemo, S., Pinto, M.A., Trusso, F., \& Iliceto, P. (2007). Primo sviluppo metalinguistico in bambini bilingui italiano-inglese. Una ricerca in contesto britannico. Rivista di Psicolinguistica Applicata. VII, 1-2, 105-125.

Figueira, A. P. C. (in press). Consciência Metalinguística (Metalinguistic Awareness). Teoria, desenvolvimento e instrumentos de avaliação.

Melogno, S., C. D’Ardia, M.A. Pinto, \& G. Levi (2012). Explaining metaphors in high-functioning Autism Spectrum Disorders children: a brief report. Research in Autism Spectrum Disorders, v.6, 683-689.

Melogno, S., C. D’Ardia, M.A. Pinto, \& G. Levi (2012). Metaphor comprehension in Autistic Spectrum
Disorders: two case studies in high-functioning children. Child Language Teaching and Therapy, V.28, 177-188.

Pafumi, M.L., Pinto, M.A., \& Iliceto, P. (2007). Habilidades de paráfrasis en alumnos bilingües español-italiano entre 14 y 17 años. Un estudio comparatívo entre Argentina e Italia, Rivista di Psicolinguistica Applicata, VII(1-2), 127-149.

Pinto, M. A. (1995). La consapevolezza metalinguistica. Teoria, sviluppo, strumenti di misurazione, Rassegna Italiana di Linguistica Applicata, 3.

Pinto, M. A., Tittone, R., \& Trusso, F. (1999). Metalinguistic Awareness, Theory, development and measurement instruments. Psicologia del bilinguismo, 2, Istituti editorial e poligrafici internazional, Pisa. Roma.

Pinto, M.A. (1999). La consapevolezza metalinguistica. Teoria, sviluppo, strumenti di misurazione, Pisa-Roma, Istituti Editoriali e Poligrafici Internazionali.

Pinto, M.A. (2011). "Long-term effects of early bilingualism on metalinguistic awareness: a study on young adults”. In P. Valore (ed.), Multilingualism. Language, Power, and Knowledge (pp. 7-27), Pisa, Edistudio.

Pinto, M.A., Candilera, G., \& Iliceto, P. (2003). Tam-2. Test di abilità metalinguistiche n.2 (9- 14 anni). La valutazione dello sviluppo metalinguistico tra scuola elementare e scuola media. Manuale di istruzioni. Roma, Scione Editore.

Pinto, M.A., \& Iliceto, P. (2007). TAM-3. Test di abilità metalinguistiche n.3. Fascia adolescenti-adulti. Roma, Carocci Faber.

Pinto, M.A., Iliceto, P., Bracone, I., \& Pontani, S. (2005). "La percezione della lingua italiana in soggetti bilingui in relazione alla percezione di Sé e dell'altro”. Rivista di Psicolinguistica Applicata, V1, 129-169.

Pinto, M.A., Iliceto, P., \& Melogno, S. (2012). Argumentative abilities in metacognition and in metalinguistics. A study on University students. European Journal of Psychology of Education. Vol. 27, 35-58.

Pinto, M.A., Melogno, S. Iliceto, P. (2008). TCM junior. Test di comprensione di metafore - junior. Scuola dell'Infanzia - scuola primaria. Carocci Faber, pp. 112.

Pinto, M.A., Titone, R., \& Gonzales Gil, M.D. (2000). La consciencia metalingüística. Teoría, desarrollo e instrumentos de medición. Pisa-Roma. Istituti Editoriali e Poligrafici Internazionali.

Pinto, M.A., Trusso, F., \& Kristiansen, K. (2002). Metalinguistic abilities in Italian-English adult bilinguals. A comparison with Italian-speaking and English-speaking monolinguals, Rivista di Psicolinguistica Applicata, II(2-3), 77-90.

Pinto, M.A.,Melogno, S., \& Iliceto, P. (2006). TCM. Test di comprensione delle metafore. Scuola elementare e scuola media. Carocci Faber.

Pinto, M.A.,Titone, R., \& Gonzales Gil (2000). La consciencia metalingüistica. Teoría, desarrollo e instrumentos de medición, Roma, Istituti Editoriali e Poligrafici Internazionali. 